\title{
Dimensiones de la emoción durante el proceso de abandono del consumo de tabaco: un apoyo a la visión motivacional del cambio*
}

\section{Dimensions of Emotion During the Cessation Process of Tobacco Consumption: Support for Motivational Vision of Change}

\author{
Carlos Gantiva Díaz ${ }^{* *}$ \\ Mónica Rodríguez \\ Milena Arias \\ Erika Rubio \\ Universidad de San Buenaventura, \\ Colombia \\ Recibido: 6 de febrero de 2012 \\ Revisado: 4 de mayo de 2012 \\ Aceptado: 30 de junio de 2012
}

\section{Resumen}

El objetivo de la investigación fue identificar las diferencias en la valoración de las dimensiones de la emoción, según el grado de disposición al cambio con respecto al abandono del consumo de tabaco. El estudio se desarrolló bajo el paradigma de visualización de imágenes afectivas con un diseño descriptivo comparativo. Participaron 90 personas y se utilizaron 51 imágenes validadas en Colombia del Sistema Internacional de Imágenes Afectivas, 9 imágenes validadas y asociadas al consumo de tabaco, la escala breve para evaluar los estadios de cambio y el SAM (Self Assessment Manikin). Los resultados muestran una valencia apetitiva, alto arousal y baja dominancia en las etapas iniciales del cambio; valencia aversiva, alto arousal y dominancia media en las etapas intermedias; y valencia neutral, bajo arousal y alta dominancia al finalizar el proceso de cambio. Los resultados se explican a partir de los modelos motivacionales del cambio.

Palabras clave: Tabaco, emociones, motivación, Colombia.

* $\quad$ Artículo de investigación.

** Correspondencia: Carlos Gantiva Díaz. Facultad de Psicología. Universidad de San Buenaventura, Colombia. Dirección postal: Carrera 8 H \# 172 20. Bogotá, Colombia. Correo electrónico: cgantiva@usbbog.edu.co, cgantiva@gmail.com 


\section{Abstract}

The objective of this research was to identify differences in the dimensions valuation of emotion according to the degree of readiness to change regarding the cessation of tobacco consumption. The study was conducted under the paradigm of affective picture viewing with a comparative descriptive design. 90 participants and 51 images validated in Colombia of the International Affective Picture System were used, as well as 9 images validated and associated with tobacco consumption, the brief scale to assess stages of change and the SAM (Self Assessment Manikin). The results show an appetitive valence, high arousal and low dominance in the early stages of change; aversive valence, arousal and dominance high average in the intermediate stages, and neutral valence, low arousal and high dominance by the end of the change process. The results are explained from the motivational models of change.

Keywords: Tobacco, emotions, motivation, Colombia

\section{Introducción}

El consumo de tabaco ha sido considerado por la Organización Mundial de la Salud - OMS como uno de los principales problemas de salud pública, se calcula que más de 6 millones de personas mueren al año por causas asociadas con el consumo de tabaco. Según los datos oficiales de la OMS que corresponden al año 2006, la prevalencia de consumo en mayores de 15 años en países latinoamericanos como Argentina es del $25.7 \%$ Brasil $12 \%$ y Chile 33.8\%(OMS, 2012).

En Colombia el consumo de tabaco se ha incrementado en los últimos años, la prevalencia de vida fue del 18.5\% en 1996 (Rodríguez, 1997), del 37.5\% en 2001 (Rumbos, 2002), del 46.1\% en 2004 (Ministerio de la Protección Social, CICAD y OEA, 2004) y del $57.1 \%$ en 2007 (Instituto Nacional de Cancerología, 2009a). Con respecto a la prevalencia del último mes se ha encontrado recientemente que el $42.8 \%$ de estudiantes universitarios consumen tabaco (Gantiva, Rodríguez, González y Vera, 2011).

Según los datos proporcionados por el Instituto Nacional de Cancerología (2009b), el consumo de tabaco está asociado directamente con el $80 \%$ de todos los cánceres de tráquea, bronquios y pulmón, al $80 \%$ de todas las enfermedades pulmonares obstructivas crónicas, al $30 \%$ de las cardiopatías isquémicas y al $40 \%$ de las enfermedades cerebrovasculares, lo cual, además del evidente costo humano y de calidad de vida, le cuesta al país más de $\$ 1.2$ billones por discapacidades 0 muerte.

El cambio de una conducta como la del consumo de tabaco ha sido explicado a partir de un proceso motivacional, en el que las personas recorren diferentes etapas, las cuales se diferencian cada una de ellas en el nivel de disposición al cambio en un periodo de tiempo determinado, es decir, del grado de motivación que presentan para abandonar la conducta de consumo (Flórez, 2007). Esta propuesta está vinculada directamente al Modelo Transteórico (MTT), el cual propone seis etapas en el proceso de cambio: precontemplación, contemplación, preparación, acción, mantenimiento y terminación (Prochaska, DiClemente y Norcross, 1992).

El concepto de etapa se ha reevaluado debido al criterio de temporalidad de las etapas y a las etiquetas de cada una de ellas, sin embargo, el concepto de niveles o grados de disposición al cambio que varían de acuerdo con el grado de motivación para abandonar o cambiar una conducta ha recibido amplia evidencia empírica (Davidson, 2001; DiClemente, 2005).

El proceso motivacional está ampliamente relacionado con la emoción, de hecho el modelo bioinformacional propuesto por Lang (1995) define a la emoción como una disposición para la acción a partir de la activación de uno de los dos sistemas motivacionales primarios (apetitivo o defensivo), 
por la percepción de un estímulo relevante para el organismo. De acuerdo con una amplia evidencia empírica, las emociones están conformadas por tres dimensiones, la valencia, la cual hace referencia al sistema motivacional activado, el apetitivo se asocia con conductas de aproximación y el defensivo con conductas de evitación; el arousal, que se refiere al grado de energía invertido en la emoción; y la dominancia, la cual se refiere al nivel de control percibido sobre la emoción (Bradley, 2009; Lang y Davis, 2006). De esta forma, los cambios en las dimensiones de la emoción proporcionan amplia información sobre el proceso de cambio de una conducta, así como del grado de motivación asociado.

El paradigma de investigación más utilizado en el modelo bio-informacional es el de visualización de imágenes afectivas (Bradley, Greenwald y Hamm, 1993). Este paradigma hace uso de un amplio conjunto de estímulos visuales de contenido emocional denominado Sistema Internacional de Imágenes Afectivas (International Affective Picture System, IAPS). EI IAPS es un instrumento compuesto por más de 1000 fotografías a color distribuidas en 20 conjuntos, tiene la ventaja de cubrir una amplia gama de estados emocionales y de representar características importantes en la vida de las personas, tales como el deporte, la comida, el sexo, la violencia, los desastres naturales y los animales, entre otras (Lang, 1995). El IAPS ha sido validado en diferentes culturas y países, entre ellos Estados Unidos (Lang, Bradley y Cuthbert, 1999, 2008); España (Moltó et ál., 1999; Vila et ál., 2001); Bélgica (Verschuere, Crombez y Koster, 2001); Chile (Dufey, Fernández y Mayol, 2011; Silva, 2011) y Colombia (Gantiva, Guerra y Vila, 2011).

El uso de imágenes afectivas para el estudio de la emoción en conductas específicas como el consumo de tabaco ha demostrado activar las dimensiones de valencia, arousal y dominancia en diferentes poblaciones (Gantiva et ál., 2012; Muñoz et ál., 2009), sin embargo, no existen estudios sobre las diferencias que se pueden presentar a lo largo del proceso de cambio, por lo cual, el objetivo de la presente investigación fue identificar las diferencias en las dimensiones de la emoción según el nivel de motivación hacia el cambio del consumo de tabaco.

\section{Método}

\section{Diseño}

La investigación se desarrolló bajo un modelo empírico analítico, con un diseño descriptivo comparativo.

\section{Participantes}

El estudio se llevó a cabo con 90 personas $(57.7 \%$ hombres y $42.3 \%$ mujeres) mayores de edad y residentes en la ciudad de Bogotá, D.C., Colombia. Los participantes tenían un media de edad de 24.9 años ( $D E=8.7$ ) y fueron divididos en tres grupos de acuerdo con el grado o nivel de motivación hacia el cambio del consumo de tabaco. El primer grupo estuvo conformado por las personas en las etapas iniciales del cambio (precontemplación y contemplación), el segundo grupo por las personas en las etapas intermedias del cambio (preparación y acción) y el tercer grupo por las personas en las etapas finales del cambio (mantenimiento y terminación). Todos los participantes tienen una historia de consumo mínima de un año y un promedio de consumo diario superior a 5 cigarrillos.

\section{Instrumentos}

Etapas de cambio para fumadores (forma breve) (Velicer et ál., 1995). Esta escala pertenece al Cuestionario del Modelo Transteórico, está compuesta por tres preguntas con opción múltiple de respuesta, que permite ubicar a la persona en cualquiera de las etapas del cambio. La validez de las escalas del cuestionario oscila entre 0.85 y 0.99 .

Imágenes afectivas relacionadas con el consumo de tabaco (Gantiva et ál., 2012). Se utilizaron nueve imágenes a color validadas para Colombia y distribuidas en siete categorías que se asocian con el consumo de tabaco, estos tipos de instrumentos se han desarrollando en otras poblacio- 
nes y bajo las mismas características (Muñoz et ál., 2009). Para esta investigación se eligieron las nueve imágenes con mayor puntaje en valencia y arousal.

Sistema Internacional de Imágenes Afectivas (IAPS) (Lang, Bradley y Cuthbert, 2008). Se utilizaron 51 imágenes validadas en población colombiana (Gantiva, Guerra y Vila, 2011) del IAPS, elegidas a partir de criterios de puntajes bajos, medios y altos en valencia, arousal y dominancia, con el objetivo de eliminar la habituación hacia las imágenes asociadas con el consumo de tabaco.

Maniquí de autoevaluación (SAM) (Lang, Bradley y Cuthbert, 1999). El SAM (Self Assessment Manikin), es un instrumento desarrollado para evaluar los estímulos visuales del IAPS. Consiste en una medida gráfica que utiliza secuencias de figuras con apariencia humanoide graduadas en intensidad, para representar los rangos de las tres dimensiones bipolares afectivas: valencia, arousal y dominancia. La validez del SAM en población colombiana muestra índices entre 0.793 y 0.970 (Gantiva, Guerra y Vila, 2011).

\section{Procedimiento}

Se construyó un conjunto de diapositivas conformado por 60 imágenes, 51 del IAPS y nueve relacionadas con el consumo de tabaco. El orden de las imágenes se alternó ubicando una imagen relacionada con el consumo de tabaco cada tres imágenes del IAPS en promedio y se balancearon las imágenes de acuerdo con las dimensiones de valencia y arousal, todo esto para eliminar el proceso de habituación. Las diapositivas se presentaron siguiendo el protocolo propuesto por Lang, Bradley y Cuthbert (1999).

La aplicación se hizo de forma grupal, presentando primero el consentimiento informado que debían firmar en la primera página del cuadernillo de evaluación, y luego las instrucciones sobre el procedimiento de evaluación a través de una grabación de audio acompañada de ilustraciones en la pantalla de proyección. La secuencia para la evaluación de cada imagen fue: (a) proyección de una diapositiva de preparación durante cinco segundos con la frase "Evalúe la siguiente diapositiva en la fila X del cuadernillo"; (b) proyección durante seis segundos de la imagen que debía ser evaluada y (c) proyección de una diapositiva durante 15 segundos con el mensaj e: "Por favor, evalúe la diapositiva en las tres dimensiones". Las instrucciones finalizaban con la evaluación de cinco imágenes de prueba con el fin de confirmar que todos los participantes habían entendido el sistema de evaluación.

Una vez tabuladas las valoraciones dadas por los participantes a cada imagen se hizo el análisis de datos utilizando el programa estadístico SPSS versión 19.0 para Windows a través de correlaciones lineales, diferencias de medias y ANOVA.

\section{Resultados}

Los resultados que se exponen a continuación corresponden a la representación gráfica en el espacio afectivo bidimensional (valencia-arousal) de las imágenes asociadas con el tabaco según el grado de disposición al cambio, así como las medias, desviaciones estándar y comparaciones múltiples en valencia, arousal y dominancia de las imágenes según el grado de motivación por abandonar el consumo de tabaco.

\section{Imágenes relacionadas con el consumo de tabaco en el espacio afectivo bidimensional}

La Figura 1 representa la distribución de las nueve imágenes relacionadas con el consumo de tabaco en el espacio afectivo bidimensional conformado por las dimensiones de valencia y arousal para las etapas iniciales, intermedias y finales del cambio. La valencia inicia en el número 1 que indica que la imagen es altamente desagradable, 5 indica que es neutra y 9 que es altamente agradable. El arousal inicia también en 1 lo que indica completa calma, 5 indica una activación moderada y 9 una alta activación. 
Como se puede observar, la imagen muestra una forma de boomerang en el que las imágenes que son altamente agradables y activantes se encuentran en el brazo superior (polo positivo), aquellas que son evaluadas como desagradables y activantes se encuentran en el brazo inferior (polo negativo) y por último las imágenes que se evalúan con una valencia neutra y activación media se ubican en la región en donde se encuentran los brazos del boomerang.

Los puntajes de las personas que se encuentran en las etapas iniciales ubican a las imágenes en el polo positivo, por el contrario, los puntajes de aquellas que se encuentran en las etapas intermedias (alta disposición al cambio) ubican a las imágenes en el polo negativo. Por último, aquellas personas que han finalizado el proceso de cambio tienen puntajes que ubican a las imágenes en una región neutral.

Se obtuvo una correlación lineal de Pearson positiva y significativa entre valencia y arousal para el polo positivo (0.61), para el polo negativo la correlación fue negativa aunque no significativa entre estas variables (-0.39). Esto indica que en las etapas iniciales del cambio la relación entre valencia y arousal es más fuerte en comparación con las etapas intermedias y finales.

Figura 1. Distribución de las imágenes relacionadas con el consumo de tabaco en el espacio afectivo bidimensional (valencia - arousal) según el grado de disposición al cambio

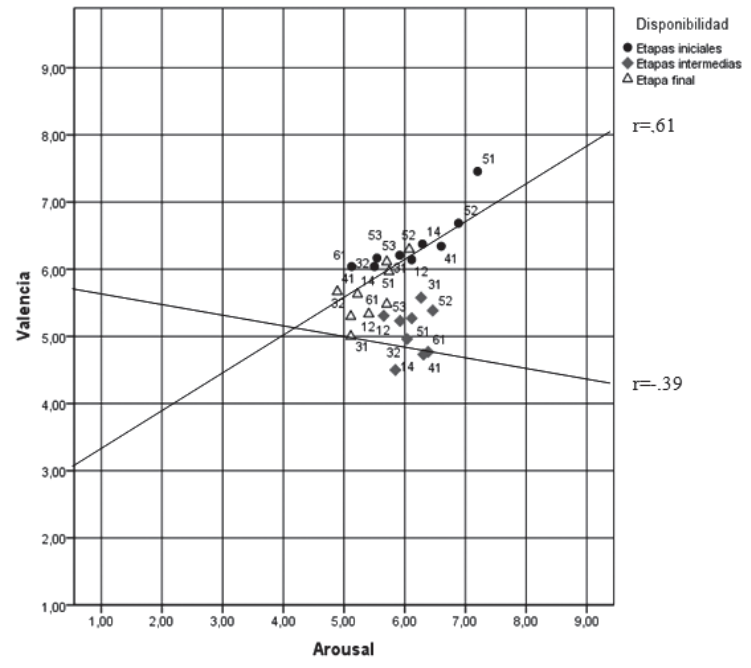

Dimensiones de la emoción en imágenes asociadas con el consumo de tabaco

En la Tabla 1 se presentan las medias y desviaciones estándar de los puntajes obtenidos en cada una de las dimensiones de la emoción según las etapas que indican una progresión en la disposición al cambio.

En la dimensión de valencia los participantes ubicados en las etapas iniciales presentan el mayor puntaje (6.3); aquellos ubicados en las etapas intermedias el menor (4.99); y las personas en las etapas finales un puntaje medio (5.58). Esto indica la activación del sistema motivacional apetitivo en las personas con poca disposición al cambio, seguido por una activación del sistema motivacional defensivo en aquellas que hacen un alto esfuerzo para lograr el cambio y una valencia neutral en las personas que lo han mantenido 0 finalizado.

En la dimensión de arousal los participantes situados en las etapas iniciales presentan un puntaje medio alto (6.03), los que se encuentran en las etapas intermedias muestran el mayor puntaje (6.15) y quienes están en las etapas finales el menor (5.37). Esto indica que al finalizar el proceso de cambio la activación ante estímulos asociados con el tabaco disminuye.

En la dimensión de dominancia las personas que se encuentran en las etapas iniciales tienen el menor puntaje (5.28), seguidas de aquellas que están en las etapas intermedias (6.31) y con el mayor puntaje las personas que están en las etapas finales (7.44). De esta forma, la percepción de control se incrementa de acuerdo con el avance en el proceso de cambio. 
Tabla 1.

Medias y desviaciones estándar de las dimensiones de la emoción según la disposición al cambio

\begin{tabular}{lcccccc}
\hline \multirow{2}{*}{$\begin{array}{c}\text { Disposición } \\
\text { al cambio }\end{array}$} & \multicolumn{2}{c}{ Valencia } & \multicolumn{2}{c}{ Arousal } & \multicolumn{2}{c}{ Dominancia } \\
\cline { 2 - 7 } & $M$ & (DE) & $M$ & $(\mathrm{DE})$ & $\mathrm{M}$ & $(\mathrm{DE})$ \\
\hline $\begin{array}{l}\text { Etapas } \\
\text { iniciales }\end{array}$ & 6.30 & .28 & 6.03 & .62 & 5.28 & .31 \\
$\begin{array}{l}\text { Etapas in- } \\
\text { termedias }\end{array}$ & 4.99 & .27 & 6.15 & .24 & 6.31 & .30 \\
$\begin{array}{l}\text { Etapas } \\
\text { finales }\end{array}$ & 5.58 & .35 & 5.37 & .39 & 7.44 & .42 \\
\hline
\end{tabular}

Nota: M: Media. DE: Desviación estándar.

\section{Comparación de las dimensiones de la emoción según el grado de motivación}

Los resultados expuestos en la Tabla 2 permiten identificar a través de un ANOVA las diferencias significativas entre las etapas iniciales, intermedias y finales en cada una de las tres dimensiones (valencia, arousal y dominancia). Como se puede observar en la dimensión de valencia hubo diferencias significativas entre todas las etapas, lo cual indica que la valencia cambia significativamente según la disposición al cambio de las personas, este elemento es fundamental, pues la valencia hace referencia al sistema motivacional activado y la disposición al cambio es también un concepto de tipo motivacional.

En la dimensión de arousal, solo hay diferencias significativas entre las etapas intermedias y finales, lo que indica una significativa disminución en la activación ante los estímulos al finalizar el proceso de cambio. Por último, en la dimensión de dominancia nuevamente se encuentra una diferencia significativa entre todas las etapas, aumentando siempre la percepción de control conforme se avanza en el proceso de cambio.
Tabla 2.

Comparación de las dimensiones de la emoción ante imágenes asociadas al tabaco según el grado de disposición al cambio

\begin{tabular}{|c|c|c|c|c|}
\hline $\begin{array}{l}\text { Dimen- } \\
\text { sión }\end{array}$ & $\begin{array}{l}\text { Disposición } \\
\text { (I) }\end{array}$ & $\begin{array}{c}\text { Disposición } \\
\text { (J) }\end{array}$ & $\begin{array}{c}\text { Diferen- } \\
\text { cia de } \\
\text { medias } \\
\text { I-J }\end{array}$ & (Sig) \\
\hline \multirow{3}{*}{ Valencia } & \multirow{2}{*}{$\begin{array}{l}\text { Etapas } \\
\text { iniciales }\end{array}$} & $\begin{array}{l}\text { Etapas } \\
\text { intermedias }\end{array}$ & $1.31^{* *}$ & .000 \\
\hline & & Etapa final & $.72^{* *}$ & .007 \\
\hline & $\begin{array}{l}\text { Etapas } \\
\text { intermedias }\end{array}$ & Etapa final & $-.58 *$ & .026 \\
\hline \multirow{3}{*}{ Arousal } & \multirow{2}{*}{$\begin{array}{l}\text { Etapas } \\
\text { iniciales }\end{array}$} & $\begin{array}{l}\text { Etapas } \\
\text { intermedias }\end{array}$ & -.11 & .911 \\
\hline & & Etapa final & .66 & .088 \\
\hline & $\begin{array}{l}\text { Etapas } \\
\text { intermedias }\end{array}$ & Etapa final & $.78^{*}$ & .043 \\
\hline \multirow{3}{*}{$\begin{array}{l}\text { Domi- } \\
\text { nancia }\end{array}$} & \multirow{2}{*}{$\begin{array}{l}\text { Etapas } \\
\text { iniciales }\end{array}$} & $\begin{array}{l}\text { Etapas } \\
\text { intermedias }\end{array}$ & $-1.02 * *$ & .002 \\
\hline & & Etapa final & $-2.15^{* *}$ & .000 \\
\hline & $\begin{array}{l}\text { Etapas } \\
\text { intermedias }\end{array}$ & Etapa final & $-1.12^{* *}$ & .001 \\
\hline
\end{tabular}

${ }^{*} \mathrm{p}<, 05$

${ }^{* *} \mathrm{p}<, 01$

\section{Discusión}

El estudio de las emociones a partir del paradigma de visualización de imágenes afectivas ha demostrado ser uno de los más sólidos y coherentes, con base en la evidencia empírica que lo soporta en los diferentes países y culturas en donde se ha aplicado (Gantiva, Guerra y Vila, 2011; Lang, Bradley y Cuthbert, 1999; 2008; Vila et ál., 2001). Estos datos han demostrado que las emociones se organizan basándose en la dimensión de valencia, seguida por la dimensión de arousal; de esta forma, el elemento que prima en las emociones es el que se active de los dos sistemas motivacionales primarios se activa (lo que determinaría una conducta de aproximación o evitación).

La dimensión de arousal está asociada con la cantidad de energía invertida y con un aumento en la probabilidad del comportamiento si se obtienen puntajes elevados. La dimensión de dominancia, 
aunque explica el menor porcentaje de la varian$z a$, es fundamental para entender el comportamiento, especialmente las conductas adictivas, ya que en ellas la percepción de control disminuye ante estímulos asociados con el consumo (Muñoz et ál., 2009).

Los resultados de esta investigación muestran que las dimensiones de la emoción cambian con respecto al avance en el proceso de cambio, en este caso con relación al consumo de tabaco. Se observa que al inicio del proceso, cuando las personas tienen una baja motivación, los estímulos asociados con el consumo de tabaco activan el sistema motivacional apetitivo, lo que implica conductas de aproximación, las cuales se hacen más probables si se tiene en cuenta que en estas etapas se encontró un mayor arousal y una menor dominancia.

Sin embargo, los resultados también muestran que en las etapas que implican mayor compromiso con el cambio y en las que se invierten los mayores recursos psicológicos, las personas cambian la valencia de los estímulos y activan el sistema motivacional defensivo, lo que se asocia con conductas de evitación, adicionalmente, mantienen el nivel de arousal lo cual indica una inversión de energía significativa para lograr las conductas de evitación y el cambio planeado.

Al terminar el proceso de cambio, se observa que la valencia de los estímulos es neutral, el arousal disminuye y la dominancia aumenta, esto indica que los procesos de cambio exitosos finalizan cuando los estímulos asociados no son ni agradables ni desagradables (valencia neutra), cuando no hay activación autónoma (bajo arousal) y cuando se percibe que hay control sobre la emoción (alta dominancia). Estos elementos validan la idea acerca de que el cambio se logra cuando a la persona le son indiferentes los estímulos asociados a lo que se ha intentado cambiar.

Estas diferencias encontradas en las dimensiones de la emoción de acuerdo con el grado de disposición al cambio son coherentes con una visión motivacional del mismo (Flórez, 2007), demostrando diferencias en la probabilidad de emitir compor- tamientos de aproximación o evitación según el grado de compromiso.

Las diferencias en las dimensiones de valencia, arousal y dominancia pueden ser explicadas a partir de un modelo motivacional, gracias a los procesos psicológicos puestos en práctica a lo largo del cambio (Flórez, 2007; Velicer, Prochaska, Fava, Norman y Redding, 1998), de esta forma, Ia ausencia de una valoración de la conducta como problema (individual o social), así como la inexistencia de expectativas de refuerzo/resultado y la baja autoeficacia generan la valoración de la conducta como apetitiva (valencia positiva), alto arousal y baja dominancia.

Sin embargo, cuando las personas ponen en práctica estos procesos cognitivos y los conductuales, tales como el contracondicionamiento, los que determinan el avance en el proceso de cambio generan una activación del sistema motivacional defensivo y con ello el inicio de conductas de evitación (Bradley, 2009), esto se ve representado claramente en los resultados de las personas que se encuentran en las etapas intermedias, aquellas que implican una mayor movilización de recursos psicológicos. Este esfuerzo que hacen las personas en estas etapas se ve representado también en el mantenimiento de la energía invertida (arousal) y el incremento en la dominancia.

Por último, y de acuerdo con los resultados, la finalización del proceso de cambio se logra cuando ninguno de los sistemas motivacionales primarios se activa, es decir, cuando los estímulos son motivacionalmente indiferentes para la persona, lo que genera que el arousal disminuya (Lang y Davis, 2006). Adicionalmente, la percepción de control aumenta, lo que estaría relacionado directamente con la autoeficacia, elemento fundamental en los modelos motivacionales del cambio (Flórez, 2007).

Los resultados de esta investigación permiten orientar los objetivos en el tratamiento de las conductas adictivas, así como en los procesos de cambio de otros comportamientos, adicionalmente son una evidencia empírica que apoya la perspectiva motivacional del cambio. 


\section{Referencias}

Bradley, M. (2009). Natural selective attention: Orienting and emotion. Psychophysiology, 46, 1-11.

Bradley, M. M., Greenwald, M. K. \& Hamm, A. O. (1993). Affective picture processing. In N. Birbaumer \& A. Ohman (Eds.), The structure of emotion: Psychophysiological, cognitive, and clinical aspects (pp. 48-68). Toronto: Hogrefe y Huber Publishers.

Davidson, R. (2001). The cycle of change. Drug and Alcohol Findings, 5, 19-24.

Diclemente, C.C. (2005). A premature obituary for the trantheorical model: a response to West (2005). Addiction, 100(8), 1046-1048.

Dufey, M., Fernández, A. M. \& Mayol, R. (2011). Adding support to cross-cultural emotional assessment: Validation of the International Affective Picture System in a Chilean sample. Universitas Psychologica, 10(2), 521-533.

Flórez, L. (2007). Psicología social de la salud: promoción y prevención. Colombia: Manual Moderno.

Gantiva, C., Guerra, P. \& Vila, J. (2011). Validación colombiana del sistema internacional de imágenes afectivas: evidencias del origen transcultural de la emoción. Acta Colombiana de Psicología, 14(2), 103-111.

Gantiva, C., Rodríguez, M., Arias, M., Rubio, E., Guerra, P. \& Vila, J. (2012). Diseño y validación de un conjunto de imágenes afectivas relacionadas con el consumo de tabaco en población colombiana. Pensamiento Psicológico, 10(2). En prensa.

Gantiva, C., Rodríguez, M., González, M. \& Vera, A. (2011). Perfil de personalidad en consumidores moderados y excesivos de sustancias psicoactivas. Psicología desde el Caribe, 28, 24-38.
Instituto Nacional de Cancerología (2009a). Encuesta mundial de tabaquismo en jóvenes (EMTAJ). En: http:// www.cancer. gov.co/documentos/ Encuesta\%20EMTAJ / ResumenBogota.pdf

Instituto Nacional de Cancerología (2009b). Salud pública. En: http:// www. medilegis.com/ BancoConocimiento/A/AM92-AA-4/ AM92AA-4.asp

Lang, P. J. (1995). The emotion probe: Studies of motivation and attention. American Psychologist, 50, 372-385.

Lang, P.J ., Bradley, M. M. \& Cuthbert, B. N. (1999). International affective picture system (IAPS): Affective ratings of pictures and instruction manual. Technical Report A-6. University of Florida, Gainesville, FL.

Lang, P.J ., Bradley, M.M. \& Cuthbert, B.N. (2008). International affective picture system (IAPS): Affective ratings of pictures and instruction manual. Technical Report A-8. University of Florida, Gainesville, FL.

Lang, P. J. \& Davis, M. (2006). Emotion, motivation, and the brain: Reflex foundations in animal and human research. Progress in Brain Research, 156, 3-34.

Ministerio de la Protección Social, CICAD \& OEA. (2004). Encuesta nacional sobre consumo SPA en jóvenes escolares 12-17 años. Colombia 2004. En: www. bvs-vspcol.bvsalud.org

Moltó, J., Montañes, S., Poy, R., Segarra, P., Pastor, M. C., Tormo, M. P., Rampirez, I., Hernández, M. A., Sánchez, M., Fernández, M. C. \& Vila, J. (1999). Un nuevo método para el estudio experimental de las emociones. El International Affective Picture System (IAPS): Adaptación española. Revista de Psicología General y Aplicada, 52, 55-87.

Muñoz, M., Viedma-del-J esús, M., FernándezSantaella, M., Peralta-Ramírez, M., CepedaBenito, A. \& Vila, J. (2009). Assessment of 
tobacco craving by means of the affective image visualization paradigm. Motivation and Emotion, 34(1), 93-103.

Organización Mundial de la Salud. (2012). Prevalence of tobacco use among adults and adolescents. Disponible en: http://gamapserver.who.int/gho/ interactive_charts/tobacco/ use/atlas. html Recuperado el 12 de enero de 2012.

Prochaska, J.O., DiClemente, C.C. \& Norcross, J. (1992). In search of how people change. American Psychologist, 47(9), 1102-1114.

Rodríguez, E. (1997). Consumo de sustancias psicoactivas en Colombia, 1996. Bogotá: Editorial Carrera 7ạ.

RUMBOS. (2002). J uventud y consumo de sustancias psicoactivas: Resultados de la encuesta nacional de 2001 en jóvenes escolarizados de 10 a 24 años. Bogotá: Presidencia de la República.

Silva, J. (2011). International Affective Picture System (IAPS) in Chile: A cross-cultural adaptation and validation study. Terapia Psicológica, 29(2), 251-258.

Velicer, W.F., Fava, J. L. Prochaska, J . O., Abrams, D. B., Emmons, K. M. \& Pierce, J. (1995). Distribution of smokers by stage in three representative samples. Preventive Medicine, 24, 401-411.

Velicer, W. F., Prochaska, J. O., Fava, J. L., Norman, G. J. \& Redding, C. A. (1998). Smoking cessation and stress management: Applications of the Transtheoretical Model of behavior change. Homeostasis, 38, 216-233.

Verschuere, B., Crombez, G. \& Koster, E. (2001). The internation affective picture system: a Flemish validation study. Psychologica Belgica, 41(4), 205-217.

Vila, J., Sánchez, M., Ramírez, I., Fernández, M., Cobos, P., Rodríguez, S. et ál., (2001). El sistema internacional de imágenes afectivas (IAPS): Adaptación española. Segunda parte. Revista de Psicología General y Aplicada, 54(4), 635-657. 